\title{
Barriers to initiation of insulin therapy in poorly controlled type 2 diabetes based on self-determination theory
}

Armin Rajab, ${ }^{1}$ Pegah Khaloo, ${ }^{1}$ Soghra Rabizadeh, ${ }^{1}$ Hamid Alemi, ${ }^{1}$ Salome Salehi, ${ }_{1}^{1}$ Reza Majdzadeh, ${ }^{2}$ Hossein Mirmiranpour, ${ }^{1}$ Assadollah Rajab, Alireza Esteghamati ${ }^{1}$ and Manouchehr Nakhjavani ${ }^{1}$

${ }^{1}$ Endocrinology and Metabolism Research Center, Vali-Asr Hospital, School of Medicine, Tehran University of Medical Sciences, Tehran, Islamic Republic of Iran (Correspondence to: M. Nakhjavani: nakhjavanim@tums.ac.ir). ${ }^{2}$ Department of Epidemiology and Biostatistics, School of Public Health, Tehran University of Medical Sciences, Tehran, Islamic Republic of Iran.

\begin{abstract}
Background: Proper glycaemic control can slow progression of diabetes complications. One of the main causes of poor glycaemic control is delayed initiation of insulin therapy.

Aims: To explain the reasons for delayed insulin initiation based on a behavioural model using patients' innate psychological needs.

Methods: We enrolled 151 patients with type 2 diabetes who had indications for insulin therapy. Thirty general practitioners (GPs) were included as care providers. Patients were studied by questionnaires evaluating components of self determination theory, such as competency, relatedness and autonomy. We also evaluated patients' attitudes towards insulin therapy using the Insulin Treatment Appraisal Scale questionnaire. GPs' attitudes towards insulin therapy were assessed with a different questionnaire.

Results: Competency of patients was scored as acceptable (14.44/20). Relatedness score was low at around 15.63/30. The findings suggested that the patients' intrinsic motivation was less than their extrinsic motivation (8.41/15 vs 15.03/20). The main barrier to insulin therapy on the patients' side was rejection of severity of illness (67.5\%). According to GPs, low compliance (96.7\%) was the main cause of delayed insulin prescription.

Conclusions: We observed that patients do not have a proper understanding about their illness. Due to the low score of relatedness as a representative of patients and care providers' relationship, we highlight the importance of educating both about insulin therapy and how they can have the most effective relationship in this process.

Keywords: type 2 diabetes, insulin therapy, psychological aspects, self-determination theory, education

Citation: Rajab A; Khaloo P; Rabizadeh S; Alemi H; Salehi S; Majdzadeh R; et al. Barriers to initiation of insulin therapy in poorly controlled type 2 diabetes based on self-determination theory. East Mediterr Health J. 2020;26(11):1331-1338. https://doi.org/10.26719/emhj.20.027

Received: 11/6/18; accepted: 25/03/19

Copyright @ C World Health Organization (WHO) 2020. Open Access. Some rights reserved. This work is available under the CC BY-NC-SA 3.0 IGO license (https://creativecommons.org/licenses/by-nc-sa/3.o/igo)
\end{abstract}

\section{Introduction}

Diabetes has become one of the biggest global health issues, due to its rapidly growing prevalence, complications and high burden of disease (1). Analyses from different countries including the Islamic Republic of Iran have demonstrated poor glycaemic control of diabetes in most patients (2). One of the main causes of poor glycaemic control is delayed initiation of insulin therapy (3-5).

The negative attitudes expressed by patients are fear of needles, self-blame for needing insulin, cost of insulin and doubts about efficacy $(6,7)$. In addition, doctors prefer to postpone prescription of insulin, which is a manifestation of clinical inertia $(6,8,9)$. Clinical inertia is defined as the failure of providers to alter therapy in the face of clear indications (6), and it is suggested causes include limited experience and knowledge along with lack of standardized guidelines $(10,11)$.

Epidemiological shift from acute to chronic diseases has required a new vision in treatment (12). In the acute-care system, patients surrender a lot of control to healthcare providers. Diabetes care requires patients and healthcare providers to collaborate in development of self-management plans (13).
Therefore, in the current study, we aimed to investigate Iranian patients' and care providers' attitudes that delay initiation of insulin therapy. There are many behavioural models that can be used to analyse patients' compliance and self-management ability. Self-determination theory (SDT) is one the most appropriate models that can be used in patients with diabetes. SDT is an approach to human motivation and personality that uses innate psychological needs, including competence, relatedness and autonomy, which appear to be essential for optimal functioning and social well-being $(14,15)$. Previous research based on SDT has revealed an association between medication adherence and autonomy and competence in chronic disease. In the present study, we used SDT to explain why patients refuse to initiate insulin therapy.

\section{Methods}

\section{Participants}

This was a descriptive cross-sectional study in 5 general medical clinics in Tehran, Islamic Republic of Iran in the summer of 2016. We randomly recruited 151 patients with poorly controlled type 2 diabetes who were candidates for insulin therapy according to the 2016 American Dia- 
betes Association/European Association for the Study of Diabetes (ADA/EASD) guidelines. There were 89 women (58.9\%) and 62 men (41.1\%), aged 29-88 (mean 56.7) years. Despite their need to start insulin therapy, none of the patients had begun. Thirty general practitioners (GPs) (18 female, 12 male; mean age 37.6 years, age range $29-54$ years) were selected randomly from general medical clinics to estimate their attitude towards insulin therapy. We chose GPs rather than specialists because in the Islamic Republic of Iran, most people go to general medical clinics and are assessed by GPs. Also, national clinical guidelines recommend that GPs are responsible for initiating insulin therapy or referring patients to specialists. Therefore, most patients with type 2 diabetes are under treatment by GPs in the Islamic Republic of Iran.

\section{Study design}

The study was divided into 2 parts: evaluation of patients' compliance with insulin therapy, and evaluation of GPs attitudes to insulin therapy. All of the questionnaires were filled out by patients in the presence of a trained GP to help them better understand the questionnaires. Data for demographic characteristics, pertinent clinical information and exposure to insulin therapy were collected from the patients. GPs were also asked to fill in a questionnaire in the presence of another GP trained in the procedure of filling in the form. This study received ethical approval from the Medical Research and Ethics Committee, Tehran University of Medical Science.

\section{Patients' questionnaires}

To measure the components of SDT, some well-known questionnaires were used. (1) Perceived Competence in Diabetes Scale (PCDS), which measures by 4 items the competency of patients in controlling their diabetes $(16,17)$. (2) Health Care Climate Questionnaire (HCCQ), which measures by 15 items the support of the health system to improve patients' autonomy. It also has a short form (containing 6 items) that is strongly correlated with the full version and highly reliable $(16,17)$. (3) The Treatment Self-Regulation Questionnaire (TSRQ) contains 2 sections (19 items) to estimate the intrinsic and extrinsic motivators of controlling diabetes, displaying autonomous versus controlled regulation of behaviour (17). (5) Insulin Treatment Appraisal Scale (ITAS) contains 20 items measuring the positive and negative attitude of patients to insulin therapy (18).

\section{Revising the questionnaires}

All of the above questionnaires were in English and had not been translated into Persian before this study; therefore, after translation, a qualitative study was done to consider the effects of social and cultural differences. Then, a group session with 15 type 2 diabetes patients was held to decide about the appropriate questions and items. After summarizing the discussions by the trained $\mathrm{GP}$, participants were asked to confirm the items in order to increase the credibility and conformability of the items. To perform content validation for development of new questionnaires, we followed Abdollahpour et al.
(19). Five experts including endocrinologists, diabetes educators and an epidemiologist gave their opinion regarding comprehensiveness, relevance and clarity of the questionnaires. They were asked to evaluate the content validity ratio for the necessity of each item in the questionnaires, and to investigate the specificity and clarity of each item using a 4-point Likert scale. After these steps, updated questionnaires were arranged in the presence of 5 patients attending the initial session and the questionnaires were reviewed for revalidation.

\section{Changes in questionnaires and validation}

The PCDS questionnaire was unchanged. It was decided to use the short form of the HCCQ questionnaire. The TSRQ questionnaire was revised to "Estimation of Internal Motives and Control Motives", including 3 items for determining internal motivations and 4 to estimate external (control) motivations. In these 3 questionnaires it was intended to use the 5-point instead of 7-point Likert scale. Thus, the total score of the questionnaires was as follows: PCDS (4-20); short HCCQ (6-15); internal motivation (3-15); and external motivation (4-20). For the ITAS questionnaire, positive attitudes ( 4 items) were excluded, and instead, only 1 item was asked from the patients to answer in the 3-point Likert scale. Two more negative attitudes were added to other items: (1) perhaps in the future insulin will become rare, for example, as a consequence of economic sanctions, and (2) insulin therapy is more expensive than oral therapy), and patients were asked to agree or disagree. This questionnaire is also called R-ITAS (a modified version) and can illustrate the frequency of negative aspects of insulin therapy, which are the issues that patients feel or believe would act as barriers to accepting insulin therapy.

Some additional questions were added based on the results of the above process and literature review (20), including whether patients were recommended to accept insulin therapy by their healthcare provider, and whether any of their acquaintances were receiving insulin therapy. The other question was based on the number of visits of patients to physicians in a year. Their attitude towards seriousness of diabetes and risk of developing its complications was measured on a 5-point Likert scale (1, very low and 5, very high).

\section{GPs' questionnaire}

The same procedure was used for GPs to prepare a questionnaire containing questions including: (1) trying to understand the reasons for not accepting insulin therapy from the patients' perspective_when GPs put themselves in the patients' place; (2) reasons for delaying or not administering insulin therapy by physicians; and (3) GPs familiarizing themselves with clinical guidelines in this area and determining the therapeutic goals based on the guidelines. The validity and reliability of the GPs' questionnaire was assessed by the above-mentioned procedure. The internal consistency of the questionnaire for 10 GPs was measured $\alpha=0.78(P<0.001)$. The trained GP who was involved in the patients' questionnaires study was not included in the GPs' questionnaire study. 


\section{Data analysis}

Data were collected and analysed by SPSS version 21 statistical software. The relationships between psychometric factors and demographic findings were evaluated by appropriate statistical tests, such as $t$ test, Mann-Whitney test and Spearman correlation analysis for nonparametric variables, and Pearson correlation analysis. Tests of normality were performed by Kolmogorov-Smirnov test. Many of the distributions were not normal, including PCDS, HCCQ, and intrinsic motivation and extrinsic motivation (obtained from modified TSRQ), (all $P<0.001$ ), so nonparametric signed rank tests were run. $P<0.05$ was considered statistically significant.

\section{Results}

\section{Baseline characteristics}

The average number of checkups per year for the 151 patients was 3.14, with significantly more in women $(P=0.002)$. The mean time that doctors spent on a patient in a usual visit was $<5$ minutes. Only 73 patients $(48.3 \%)$ were recommended to initiate insulin therapy. This number was significantly lower in patients who were under supervision of a GP [odds ratio (OR) $=5.56, P<0.001$, $\left.\chi^{2}=25.4\right]$. Forty $(26.5 \%)$ patients developed diabetes complications (Table 1).

Baseline fasting blood sugar, haemoglobin Alc concentration, body mass index (BMI), systolic and diastolic blood pressure, and duration of diabetes are shown in Table 2. Mean BMI was significantly higher in female patients $(P<0.001, t=10.99)$.

We asked patients to score the seriousness of diabetes out of 5 (1, very low and 5 , very high). The mean score was 3.44. Only 17 (11.3\%) patients described diabetes as having low seriousness. We also asked patients to evaluate their risk of developing diabetes complications by giving a risk score of 1 (very low), 2 (low), 3 (moderate), 4 (high) or 5 (very high). The number of patients in each category was $73(48.3 \%), 52(34.4 \%), 12(7.9 \%), 13(8.6 \%)$ and $1(0.7 \%)$, respectively. Mean score was 1.79 .

\section{Psychometric findings}

The results for PCDS, HCCQ and modified TSRQ (intrinsic and extrinsic motivation) are shown in Table 3. There was no significant difference in controlled motivation, self-motivation and perceived competence between patients who were under supervision of a GP compared with an internist. HCCQ scores were significantly higher in patients working with an internist $(P=0.003, z=2.94)$ and had a positive correlation with the time doctors spent in a usual visit $(P<0.001, z=5.78)$. Self-motivation scores were also higher in this group. Age had an inverse correlation with PCDS $(P<0.001)$ and a positive correlation with controlled motivation $(P<0.001 ; \mathrm{r}=0.31)$. HCCQ, self-motivation and PCDS scores were lower in patients with diabetes complications $(P<0.001, z=2.4 ; P<0.001$, $\mathrm{z}=2.55 ; \mathrm{P}=0.011, \mathrm{z}=4.47$, respectively).

\begin{tabular}{|c|c|c|}
\hline Characteristics & No. & $\%$ \\
\hline \multicolumn{3}{|l|}{ Sex } \\
\hline Male & 62 & 41.1 \\
\hline Female & 89 & 58.9 \\
\hline \multicolumn{3}{|l|}{ Education } \\
\hline Illiterate & 10 & 6.6 \\
\hline Below diploma & 85 & 56.3 \\
\hline Diploma & 34 & 22.5 \\
\hline Higher education & 22 & 14.6 \\
\hline \multicolumn{3}{|l|}{ Mean annual income (US\$) } \\
\hline$<2400$ & 14 & 9.3 \\
\hline $2400-4200$ & 82 & 54.3 \\
\hline$>4200$ & 55 & 36.4 \\
\hline \multicolumn{3}{|l|}{ Physician level of practice } \\
\hline General practitioner & 83 & 55 \\
\hline Internist (Endocrinologist) & 68 & 45 \\
\hline \multicolumn{3}{|l|}{ Long-term complications } \\
\hline Yes & 40 & 26.5 \\
\hline No & 111 & 73.5 \\
\hline \multicolumn{3}{|l|}{ Family history of type 2 diabetes } \\
\hline Yes & 99 & 65.5 \\
\hline No & 52 & 34.4 \\
\hline \multicolumn{3}{|c|}{ Family history of insulin treatment } \\
\hline Yes & 59 & 39.1 \\
\hline No & 92 & 60.9 \\
\hline
\end{tabular}

\section{Patient attitudes toward insulin therapy}

Based on the findings of the R-ITAS questionnaire developed from modification of ITAS, the following results were obtained. Only 39 (25.8\%) patients believed in insulin efficacy; 82 (54.3\%) did not have enough knowledge; and $30(19.9 \%)$ thought that insulin was ineffective for treatment of diabetes. The most common reasons for patients refusing insulin therapy are shown in Figure 1. The main reason was that they did not believe in the severity of their disease. Only 26 (17.2\%) patients were worried about hypoglycaemia after initiating insulin therapy and it was not one of the common reasons of avoiding insulin therapy. Fear of needles $(P=0.02, t=3.25)$ and difficulty with injecting the right amount of insulin $(P=0.035, t=3.16)$ were more prevalent in older patients. The number of patients who agreed with insulin efficacy $(n=16 ; 27.1 \%)$ was significantly lower among those who knew another patient using insulin $(P<0.001)$. Patients with lower level of education, including illiteracy and below diploma level $(n=53 ; 55.8 \%)$, believed that they did not have enough knowledge about whether insulin was effective, compared with patients with higher level of education $\left(n=23\right.$; 41.0\% $\left(P=0.049, \chi^{2}=9.57\right)$. Patients with lower level of education agreed more than others that managing insulin injections takes a lot of time and energy $(\mathrm{OR}=2.44,95 \%$ confidence interval $=1.14-5.2, \mathrm{P}=$ $0.012, \chi^{2}=6.30$ ). 


\begin{tabular}{|c|c|c|c|c|}
\hline Characteristics & Minimum & Maximum & Mean & SD \\
\hline FBS (mg/dl) & 54 & 597 & 183.73 & 74.96 \\
\hline HbAlc (\%) & 7.50 & 14.60 & 9.42 & 1.11 \\
\hline \multicolumn{5}{|l|}{ BMI $\left(\mathrm{kg} / \mathrm{m}^{2}\right)$} \\
\hline Male & 13.29 & 54.09 & 27.08 & 4.39 \\
\hline Female & 15.06 & 54.09 & 29.38 & 5.17 \\
\hline SBP (mmHg) & 91 & 207 & 132.99 & 20.64 \\
\hline DBP (mmHg) & 51 & 130 & 79.53 & 11.76 \\
\hline Duration of diabetes (yr) & 1 & 30 & 8.46 & 5.61 \\
\hline
\end{tabular}

$B M I=$ body mass index $; \mathrm{DBP}=$ diastolic blood pressure; $\mathrm{FBS}=$ fasting blood sugar $; \mathrm{HbA1c}=$ haemoglobin $\mathrm{Alc} ; \mathrm{SBP}=$ systolic blood pressure; $S \mathrm{D}=$ standard deviation .

\section{GP attitudes}

From the GPs' perspective, the most common reasons for patient refusal of insulin are shown in Figure 2. The most common reasons for GPs delaying insulin prescription were: expectation of low patient compliance $(n=29$; $96.7 \%$ ); fear of hypoglycaemia $(n=25 ; 83.3 \%)$; insulin is the last choice of therapy $(n=20 ; 66.7 \%)$; and lack of suitable guidelines and training ( $n=16 ; 53.3 \%)$. Twenty-four GPs believed they needed to refer patients to an internist or endocrinologist for insulin initiation, while the other 6 believed that they were able to initiate insulin therapy by themselves. Only 11 GPs managed diabetes based on standardized guidelines (ADA/EASD), and only 5 had read up-to-date guidelines.

\section{Discussion}

We aimed to determine the barriers to initiation of insulin therapy in patients with type 2 diabetes, who had clear indications for starting insulin therapy but were not using insulin. Our results showed that more than half of our patients did not have enough knowledge about insulin efficacy. This is one manifestation of inadequate knowledge of patients about diabetes (21). Only $17.2 \%$ of patients found themselves at risk of diabetes complications. Denial of the severity of the disease and denial of the failure of oral agents were the main reasons for refusing insulin therapy among patients. It means that they cannot accept that their disease has progressed. This can be explained by the chronic nature of diabetes and the delayed appearance of complications. In other words patients do not worry about the future consequences of the disease because they feel healthy at the present time. Patients' belief that injecting insulin is embarrassing was another noticeable reason for their delaying initiation of insulin therapy. This highlights the importance of injection stigma and how it affects the proper treatment of diabetes. Other reasons expressed by participants included difficulties in fulfilling daily responsibilities and difficulties with injecting the right amount of insulin.

Doctors assumed that fear of needles and the pain caused by injection were the main reasons for rejecting insulin therapy among patients; however, as mentioned before, patients feel embarrassed about insulin injection and are not necessarily frightened of it. In our study, $51.7 \%$ of patients were not recommended to take insulin at all despite the medical indicators showing a significant need for it. Care providers should endeavour to explain more thoroughly the benefits of taking insulin and try to make patients comfortable with starting treatment early. This would break the cycle of clinical inertia. This is more common among patients who are under supervision of a GP (22). Our study showed similar results. Low compliance and high possibility of hypoglycaemia were the main reasons GPs expressed for avoiding insulin prescription. We observed that just $17.2 \%$ of patients were worried about hypoglycaemia as a result of insulin therapy compared to $83.3 \%$ of GPs. The reason could be lack of knowledge of people about insulin therapy and the risk of hypoglycaemia. It requires more complete future investigation in the future. Since most patients with diabetes attend GPs for treatment (23) we need to educate GPs and establish standardized guidelines. A significant majority $(63.3 \%)$ of our participants complained about a lack of national guidelines for diabetes treatment. There are clinical guidelines discussing the principles needed to be considered by doctors in every visit, although many doctors do not have access to these guidelines; therefore, they may be neglected in usual visits $(10,24)$.

\begin{tabular}{lcccc}
\hline Table 3 Psychometric findings & Minimum & Maximum & Mean & SD \\
\hline PCDS & 4 & 19 & 14.44 & 3.15 \\
HCCQ & 6 & 28 & 15.63 & 4.67 \\
Intrinsic motivation & 4 & 14 & 8.41 & 2.51 \\
Extrinsic motivation & 5 & 19 & 15.03 & 2.7 \\
\hline
\end{tabular}

HCCQ = Health Care Climate Questionnaire; $P C D S=$ Perceived Competence in Diabetes Scale $S \mathrm{SD}=$ standard deviation . 


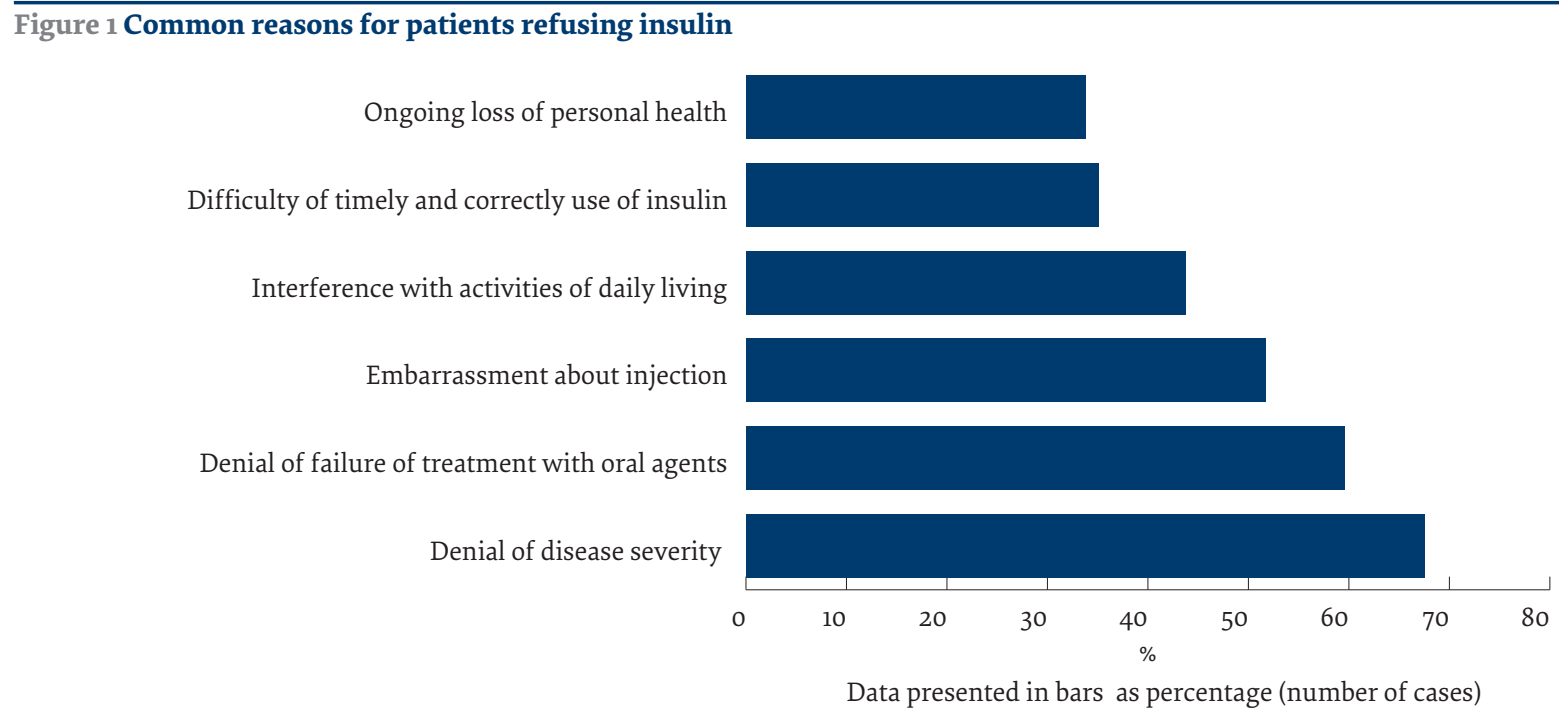

Psychometric findings showed a reasonable score (14.4/20) for PCDS. This index indicates the competency of diabetic patients to control their disease (25). Our results demonstrated an inverse association between age and PCDS score. This indicates that ageing has a negative impact on how patients feel about their competence in self-management. These results confirm previous studies (26). Older patients need more help in order to enhance this index, especially for complicated procedures such as insulin therapy.

Contrary to PCDS index, the mean HCCQ score was not positive enough. It was almost half of the maximum score. This index reflects the relationship between care providers and patients and how healthcare systems support patients for self-management (27). Numerous studies have suggested that low HCCQ score and poor communication with care providers could be one of the reasons for patients refusing insulin therapy (27). Moreover, low HCCQ score aggravates the negative attitudes toward insulin therapy among patients (28). A well-established relationship between doctors and patients improves the latter's attitude (27). A low HCCQ score indicates poor insight of doctors about diabetes treatment and the fact that they should play the role of counsellor for patients (13). We found similar results in our study since the reasons patients expressed for refusing insulin therapy varied from those doctors assumed. Grant et al. described the negative impacts of these prejudgments on initiation of insulin therapy (29).

We studied the components of TSRQ index including intrinsic motivation and extrinsic motivation separately. Extrinsic motivations were significantly higher compared to intrinsic motivations; however, it is reported that intrinsic motivation is more important for initiation of and adherence to insulin therapy (17). Extrinsic motivation on its own can be counterproductive. It is necessary for the internalization of the requested behaviour but if the internalization does not occur properly it can make the patients disappointed rather than motivated $(14,15)$. In our study intrinsic motivations had the lowest scores among SDT parameters. That is because patients do not find themselves at risk of diabetes complications.

\section{Figure 2 Common reasons for patients refusing insulin from general practitioners' point of view}

Denial of disease severity

Pain of injection
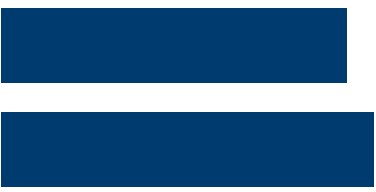

Interference with responsibilities

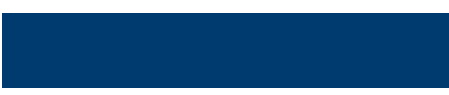

Difficulty of adjusting insulin dose

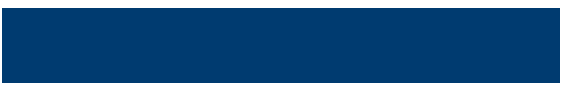

Fear of injection

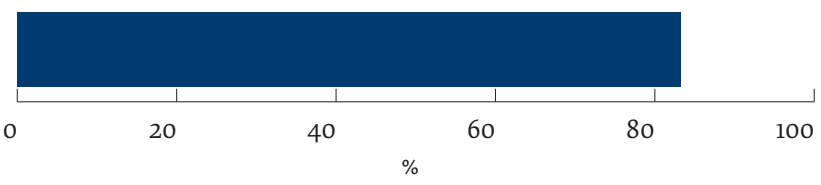

Data presented in bars as percentage (number of cases) 
It is reported that this issue can minimize patients' motivation to initiate more-intensive therapies such as insulin therapy (30).

One particularly interesting finding of our study was that patients who knew a person using insulin did not believe in insulin efficacy. It can be explained by the poor glycaemic control of patients when initiating insulin therapy $(3,31)$. In other words, patients who accept insulin therapy are those who are at later stages of the disease but people suppose that insulin has caused complications.

We showed that participants with lower compared with higher educational level had uncertainty about the efficacy of insulin therapy. However, agreement about efficacy of insulin therapy among participants with higher education level was not as high as we expected. Perhaps these findings are based on the fact that patients with low and high education level had little knowledge about diabetes and its treatment, although the latter group had more definite opinions. In addition, highly educated patients disagreed more with the idea that managing insulin injections takes a lot of time and energy. These results may explain the self-confidence of patients with higher level of education.

There were some limitations to our study. First, benchmark scores for the questionnaires have not yet been determined in the Islamic Republic of Iran. Therefore, we tried just to show the components of SDT among Iranian patients themselves. Second, we were not able to evaluate the general knowledge of our participants about diabetes because of low cooperation and large number of questionnaires. Third, we only included GPs as care providers.

In conclusion, initiation of insulin therapy is dependent on multiple factors. We observed that patients do not have a proper understanding of their illness and require improved intrinsic motivation. Care providers do not have an accurate understanding of what the patients' psychological barriers to treatment are. Our study highlights the importance of educating both patients and care providers about insulin therapy and how they can have effective communication in this relationship.

\section{Acknowledgement}

The authors wish to thank all patients for their participation and kind cooperation.

Funding: None.

Competing interests: None declared.

\section{Obstacles face à la mise en place de l'insulinothérapie dans le diabète de type $\mathbf{2}$ mal contrôlé selon la théorie de l'autodétermination}

\section{Résumé}

Contexte : Un contrôle adéquat de la glycémie permet de ralentir la progression des complications du diabète. Le retard dans la mise en place de l'insulinothérapie constitue l'une des principales causes d'un mauvais contrôle de la glycémie.

Objectifs : Expliquer les raisons du retard de la mise en place du traitement par insuline sur la base d'un modèle comportemental fondé sur les besoins psychologiques innés des patients.

Méthodes : Nous avons recruté 151 patients atteints de diabète de type 2 pour lesquels l'insulinothérapie était indiquée. Une trentaine de médecins généralistes ont été inclus en qualité de prestataires de soins. L'étude a été menée au moyen de questionnaires évaluant des composantes de la théorie de l'autodétermination, telles que la compétence, l'affiliation et l'autonomie. Nous avons également évalué les attitudes des patients vis-à-vis de l'insulinothérapie à l'aide du questionnaire de l'échelle d'évaluation de l'insulinothérapie (Insulin Treatment Appraisal Scale). Les attitudes des médecins généralistes visà-vis de l'insulinothérapie ont été évaluées au moyen d'un questionnaire différent.

Résultats : La compétence des patients a été jugée acceptable (14,44/20). Le score se rapportant à l'affiliation était faible, à environ 15,63/30. Les résultats suggèrent que la motivation intrinsèque des patients était inférieure à leur motivation extrinsèque (8,41/15 contre 15,03/20). Du côté des patients, le rejet de la gravité de la maladie (67,5\%) constituait le principal obstacle à la mise en place de l'insulinothérapie. Selon les médecins généralistes, une faible observance $(96,7 \%)$ était la principale cause de retard dans la prescription d'insuline.

Conclusions : Nous avons observé que les patients ont une mauvaise compréhension de leur maladie. En raison de la faiblesse du score concernant l'affiliation, en tant qu'élément représentant la relation entre les patients et les prestataires de soins, nous soulignons l'importance d'une meilleure sensibilisation des malades et soignants à l'insulinothérapie et de la manière de mettre en place une relation efficace. 


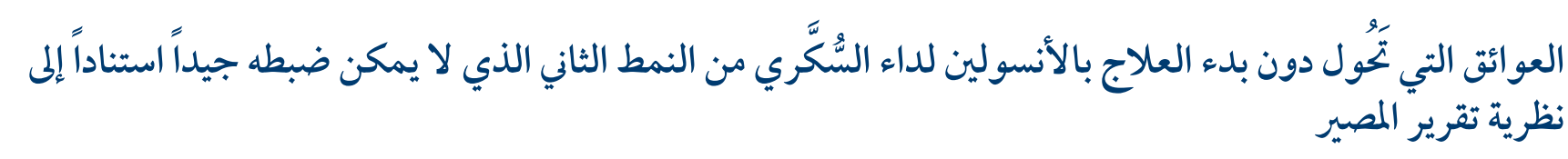

أرمين رجب، بيجا خالو، صغرى رابي زاده، حمد العليمي، سالومي صالحي، رضا مجدزاده، حسين ميرميرانبور، أسد الله رجب، علي رضا

إستغاماتي، منو جهر نخجوجاني

الخلاصة

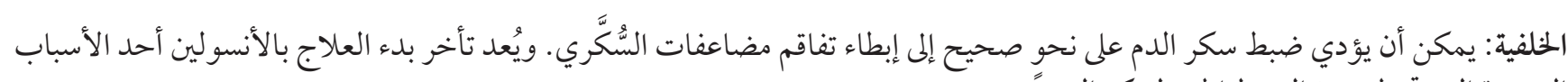

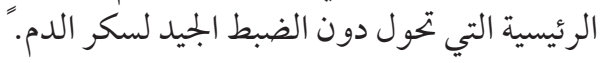

الأهداف: هدفت هذه الدر اسة إلى شرح أسباب تأخّر بدء العلاج بالأنسولين بناءً على نموذج سلوكي يستند إلى احتياجات المرضى النفسية الفطرية.

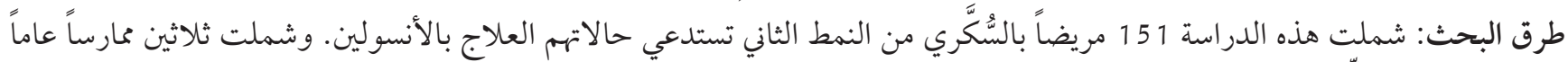

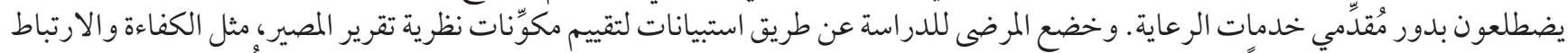

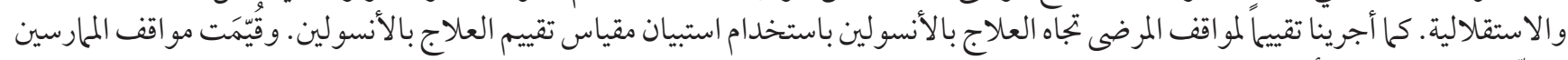

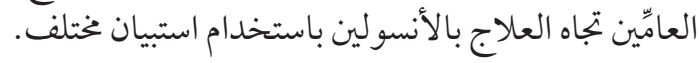

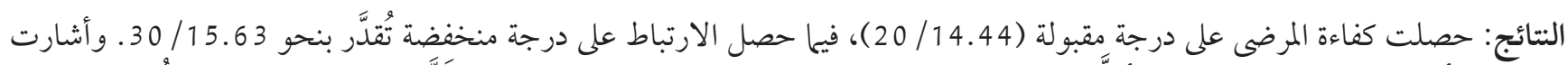

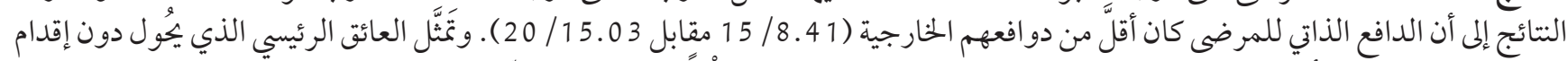

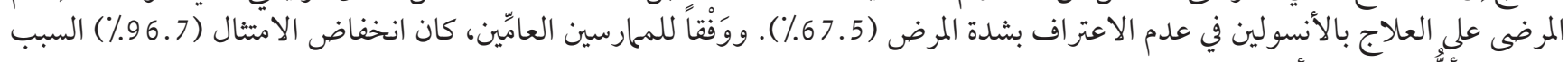

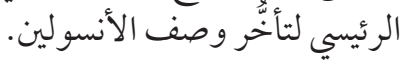

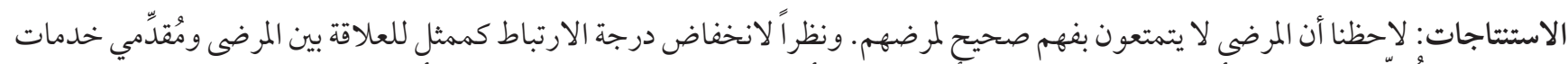

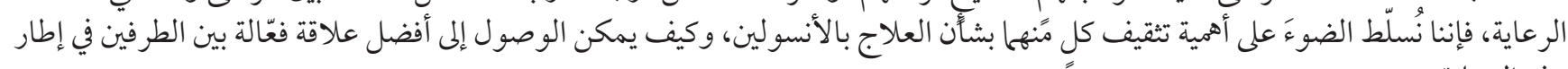
هذه العملية.

\section{References}

1. IDF diabetes atlas. Brussels: International Diabetes Federation; 2015.

2. ADVANCE Collaborative Group, Patel A, MacMahon S, Chalmers J, Neal B, Billot L, et al. Intensive blood glucose control and vascular outcomes in patients with type 2 diabetes. N Engl J Med. 2008 Jun 12;358(24):2560-72. http://dx.doi.org/10.1056/NEJMoa0802987 PMID:18539916

3. Calvert MJ, McManus RJ, Freemantle N. Management of type 2 diabetes with multiple oral hypoglycaemic agents or insulin in primary care: retrospective cohort study. Br J Gen Pract. 2007 Jun;57(539):455-60. PMID:17550670

4. Russell-Jones D, Pouwer F, Khunti K. Identification of barriers to insulin therapy and approaches to overcoming them. Diabetes Obes Metab. 2018 Mar;20(3):488-496. http://dx.doi.org/10.1111/dom.13132. PMID:29053215

5. Ates E, Set T, Saglam Z, Tekin N, Karatas Eray I, Yavuz E, et al. Insulin initiation status of primary care physicians in Turkey, barriers to insulin initiation and knowledge levels about insulin therapy: a multicenter cross-sectional study. Prim Care Diabetes. 2017 Oct;11(5):430-6. http://dx.doi,org/10.1016/j.pcd.2017.05.003 PMID:28579057

6. Peyrot, M., Rubin RR, Lauritzen T, Skovlund SE, Snoek FJ, Matthews DR, et al. Resistance to insulin therapy among patients and providers: results of the cross-national Diabetes Attitudes, Wishes, and Needs (DAWN) study. Diabetes Care. 2005 Nov;28(11):2673-9. http://dx.doi.org/10.2337/diacare.28.11.2673 PMID:16249538

7. Krall, J., Gabbay R, Zickmund S, Hamm ME, Williams KR, Siminerio L. Current perspectives on psychological insulin resistance: primary care provider and patient views. Diabetes Technol Ther. 2015 Apr;17(4):268-74. http://dx.doi.org/10.1089/dia.2014.0268 PMID:25551737

8. American Diabetes Association. Standards of medical care in diabetes. Diabetes Care, 2015 Jan;38(Suppl 1). https://care.diabetesjournals.org/content/suppl/2014/12/23/38.Supplement_1.DC1/January_Supplement_Combined_Final.6-99.pdf

9. Brunton, SA. Implementing treatment guidelines for type 2 diabetes in primary care. Postgrad Med. 2009 Apr;121(2):125-38. http://dx.doi.org/10.3810/pgm.2009.03.1985

10. Bernard AM, Anderson L, Cook CB, Phillips LS. What do internal medicine residents need to enhance their diabetes care? Diabetes Care. 1999 May;22(5):661-6. http://dx.doi.org/10.2337/diacare.22.5.661 PMID:10332662

11. Drass J, Kell S, Osborn M, Bausell B, Corcoran J Jr, Moskowitz A, et al. Diabetes Care for Medicare Beneficiaries: Attitudes and behaviors of primary care physicians. Diabetes Care, 1998 Aug;21(8):1282-7. http://dx.doi.org/10.2337/diacare.21.8.1282 PMID:9702434

12. Anderson RM, Funnell MM. Compliance and Adherence are Dysfunctional Concepts in Diabetes Care. Diabetes Educ. 2000 JulAug;26(4):597-604. http://dx.doi.org/10.1177/014572170002600405 PMID:11140071 
13. Anderson RM, Funnell MM. Patient empowerment: reflections on the challenge of fostering the adoption of a new paradigm. Patient Educ Couns. 2005 May;57(2):153-7. http://dx.doi.org/10.1016/j.pec.2004.05.008 PMID:15911187

14. Ryan RM, Deci EL. Self-determination theory and the facilitation of intrinsic motivation, social development, and well-being. Am Psychol. 2000 Jan;55(1):68-78. http://dx.doi.org/10.1037//0003-066x.55.1.68 PMID:11392867

15. Vallerand RJ. Deci and Ryan's self-determination theory: a view from the hierarchical model of intrinsic and extrinsic motivation. Psychol Inq. 2000;11(4):312-8. https://www.jstor.org/stable/1449629?seq=1

16. Williams GC. Patrick H, Niemiec CP, Williams LK, Divine G, Lafata JE, et al. Reducing the health risks of diabetes: how self-determination theory may help improve medication adherence and quality of life. Diabetes Educ. 2009 May-Jun;35(3):484-92. http://dx.doi.org/10.1177/0145721709333856 PMID:19325022

17. Williams GC, McGregor HA, Zeldman A, Freedman ZR, Deci EL. Testing a self-determination theory process model for promoting glycemic control through diabetes self-management. Health Psychol, 2004 Jan;23(1):58-66. http://dx.doi.org/10.1037/02786133.23.1.58 PMID:14756604

18. Snoek FJ, Skovlund SE, Pouwer F. Development and validation of the insulin treatment appraisal scale (ITAS) in patients with type 2 diabetes. Health Qual Life Outcomes. 2007 Dec 20;5:69. http://dx.doi.org/10.1186/1477-7525-5-69 PMID:18096074

19. Abdollahpour I, Nedjat S, Noroozian M, Majdzadeh R. Performing content validation process in development of questionnaires. Iran J Epidemiol. 2011;6(4):66-74. http://irje.tums.ac.ir/browse.php?a_id=70\&sid=1\&slc_lang=en

20. Kunt T, Snoek FJ. Barriers to insulin initiation and intensification and how to overcome them. Int J Clin Pract Suppl. 2009 Oct;164:6-10. http://dx.doi.org/10.1111/j.1742-1241.2009.02176.x PMID:19751453

21. Rezaaei J, Rezaaei M, Razlaansari HA, Khaaledi B, Taymoori B, Khaatooni AR, et al. Self-care in insulin therapy among type I diabetics referring to the Diabetes Research Center (Kermanshah,1999). J Kermanshah Univ Med Sci. 2003;6(4):e81165 (in Persian). https://jkums.com/en/articles/81165.html

22. Ziemer DC, Miller CD, Rhee MK, Doyle JP, Watkins C Jr, Cook CB et al. Clinical inertia contributes to poor diabetes control in a primary care setting. Diabetes Educ. 2005 Jul-Aug;31(4):564-71. http://dx.doi.org/10.1177/0145721705279050 PMID:16100332

23. Cobble ME. Initiating and intensifying insulin therapy for type 2 diabetes: why, when, and how. Am J Ther. 2009 JanFeb;16(1):56-64. http://dx.doi.org/10.1097/MJT.obo13e3181966bfo PMID:19142156

24. Giangola J, Olohan K, Longo J, Goldstein JM, Gross PA. Barriers to hyperglycemia control in hospitalized patients: a descriptive epidemiologic study. Endocr Pract. 2008 Oct;14(7):813-9. http://dx.doi.org/10.4158/EP.14.7.813 PMID:18996808

25. Anderson RM, Funnell MM, Fitzgerald JT, Marrero DG. The Diabetes Empowerment Scale: a measure of psychosocial self-efficacy. Diabetes Care. 2000 Jun;23(6):739-43. http://dx.doi.org/10.2337/diacare.23.6.739 PMID:10840988

26. Nam S, Chesla C, Stotts NA, Kroon L, Janson SL. Factors associated with psychological insulin resistance in individuals with type 2 diabetes. Diabetes Care. 2010 Aug;33(8):1747-9. http://dx.doi.org/10.2337/dc10-0099 PMID:20435797

27. Heisler M, Vijan S, Anderson RM, Ubel PA, Bernstein SJ, Hofer TP. When do patients and their physicians agree on diabetes treatment goals and strategies, and what difference does it make? J Gen Intern Med. 2003 Nov;18(11): 893-902. http://dx.doi. org/10.1046/j.1525-1497.2003.21132.x PMID:14687274

28. Korytkowski M. When oral agents fail: practical barriers to starting insulin. Int J Obes Relat Metab Disord. 2002 Sep;26 Suppl 3:S18-24. http://dx.doi.org/10.1038/sj.ijo.0802173 PMID:12174319

29. Grant R, Adams AS, Trinacty CM, Zhang F, Kleinman K, Soumerai SB. Relationship between patient medication adherence and subsequent clinical inertia in type 2 diabetes glycemic management. Diabetes Care. 2007 Apr;30(4):807-12. http://dx.doi. org/10.2337/dc06-2170 PMID:17259469

30. Anderson RJ, Freedland KE, Clouse RE, Lustman PJ. The Prevalence of Comorbid Depression in Adults With Diabetes. Diabetes Care. 2001 Jun;24(6):1069-78. http://dx.doi.org/10.2337/diacare.24.6.1069 PMID:11375373

31. Khunti K, Wolden ML, Thorsted BL, Andersen M, Davies MJ. Clinical inertia in people with type 2 diabetes. Diabetes Care. 2013 Nov;36(11):3411-7. https://doi.org/10.2337/dc13-0331 